\title{
BIRTH WEIGHTS OF SOUTH AFRICAN BABIES (II.) EFFECT OF BIRTH RANK ON BIRTH WEIGHT
}

BY

\author{
EVA J. SALBER* and EVELYN S. BRADSHAW \\ Institute of Family and Community Health, Union Health Department, Durban, \\ Union of South Africa
}

This paper is a report on the birth weights of groups of South African babies with special reference to the effect of birth rank on these weights. This is the second paper of a series, the first of which (Salber and Bradshaw, 1951) dealt with the effect of race and sex on birth weight.

\section{MATERIAL AND Method}

The data were collected from various hospitals and nursing homes in Durban, Pietermaritzburg, and Capetown, as shown below:

3,165 European babies from two private nursing homes in Durban.

1,057 coloured (i.e. half-caste) $\dagger$ babies from a mission hospital in Durban, and two provincial hospitals, one in Capetown and one in Pietermaritzburg.

2,188 Bantu babies from a mission hospital in Durban.

1,391 Indian babies from a provincial hospital in Pietermaritzburg, a mission hospital in Durban, and a government-aided hospital in Durban.

The data extracted in all cases consisted of birth weight, race of mother, sex of child, and birth rank of child. Abortions and multiple births were excluded. The numbers of cases used here are not identical with those used in the previous paper, since those in which birth rank was not recorded had to be omitted. Additional data which included birth rank was collected for this paper. In considering the birth rank of the child, previous miscarriages were included.

Frequency distributions of the birth ranks for the different racial groups were drawn up (see Appendix, pp. 252-53). Means and standard deviations of the birth weights for the different birth ranks were calculated for the races and sexes separately. Where differences occurred the significance of these differences was also calculated.

\section{RESULTS}

Table I (overleaf) shows that over 80 per cent. of the European babies fall into the first two birth ranks, whereas for the Indian babies 80 per cent. covers the first five birth ranks, and over 5 per cent. of the Indian babies are of the tenth or higher birth ranks. The Coloured and Bantu babies fall between these two

* Senior Bursar, Council for Scientific and Industrial Research.

$\dagger$ Coloured people are persons of mixed race, at least one of whose progenitors is a European. 
TABLE I

Percentage Distribution by Birth Rank (both Sexes)

\begin{tabular}{c|c|c|c|c}
\hline Birth Rank & European & Coloured & Bantu & Indian \\
\cline { 2 - 3 } & $49 \cdot 0$ & $37 \cdot 3$ & $32 \cdot 0$ & $29 \cdot 0$ \\
2 & $32 \cdot 0$ & $24 \cdot 1$ & $25 \cdot 7$ & $18 \cdot 8$ \\
3 & $13 \cdot 6$ & $12 \cdot 1$ & $16 \cdot 5$ & $12 \cdot 6$ \\
4 & $3 \cdot 2$ & $7 \cdot 5$ & $9 \cdot 4$ & $9 \cdot 3$ \\
5 & $1 \cdot 3$ & $4 \cdot 7$ & $6 \cdot 4$ & $8 \cdot 0$ \\
6 and 7 & $0 \cdot 6$ & $7 \cdot 4$ & $6 \cdot 4$ & $10 \cdot 6$ \\
8 and 9 & $0 \cdot 2$ & $3 \cdot 8$ & $2 \cdot 2$ & $6 \cdot 6$ \\
$10+$ & $0 \cdot 1$ & $3 \cdot 1$ & $1 \cdot 4$ & $5 \cdot 1$ \\
\hline Total & $100 \cdot 0$ & $100 \cdot 0$ & $100 \cdot 0$ & $100 \cdot 0$ \\
\hline
\end{tabular}

extremes, with the Coloured babies showing slight predominance over the Bantu in the higher birth ranks.

Table II and the Figure show that the mean birth weight increases with increasing birth rank up to Rank 4 in all the racial groups, although in no group is there a steady rise from Rank 1 to the highest rank. The European and Indian groups rise to a peak (which lasts longer in the Indian group) and the mean birth weights fall for the highest birth rank group, although remaining higher than Rank 1 babies. In the Coloured group, with the exception of the slight drop in mean birth weight for Ranks 6 and 7, the curve is very similar to that found in the European and Indian groups. The Bantu curve, however, seems to differ from the other three, in that there is a drop after Rank 4, carried on to Ranks 6 and 7 , after which the mean birth weights rise again to a peak at Rank $10+$. It may be that this is a question of numbers, as none of the differences between mean birth weights for the higher birth ranks are significant.

Although the mean birth weights follow the patterns previously described, the only significant differences found were between Rank 1 and the other ranks (Table II), with two exceptions in which Rank 2 babies were also significantly lower than two of the higher ranks.

It has been shown (Salber and Bradshaw, 1951) that significant differences existed between the mean birth weights of the four racial groups, with the exception of that between Coloured and Bantu babies. In the light of the very different distribution of ranks found in the four racial groups (see Table I), this was considered to be a possible factor in accounting for the difference found between mean birth weights. Accordingly, like ranks were compared with each other in the four racial groups, and as the sex ratio appeared to vary in the different ranks, boys and girls were considered separately (see Table III, overleaf).

Table III shows that for both sexes and for all ranks, the same differences exist as those found previously. That is to say that, in all ranks, European babies are significantly higher, Indians are significantly lower, and there is no significant difference between the Coloured and Bantu groups. 


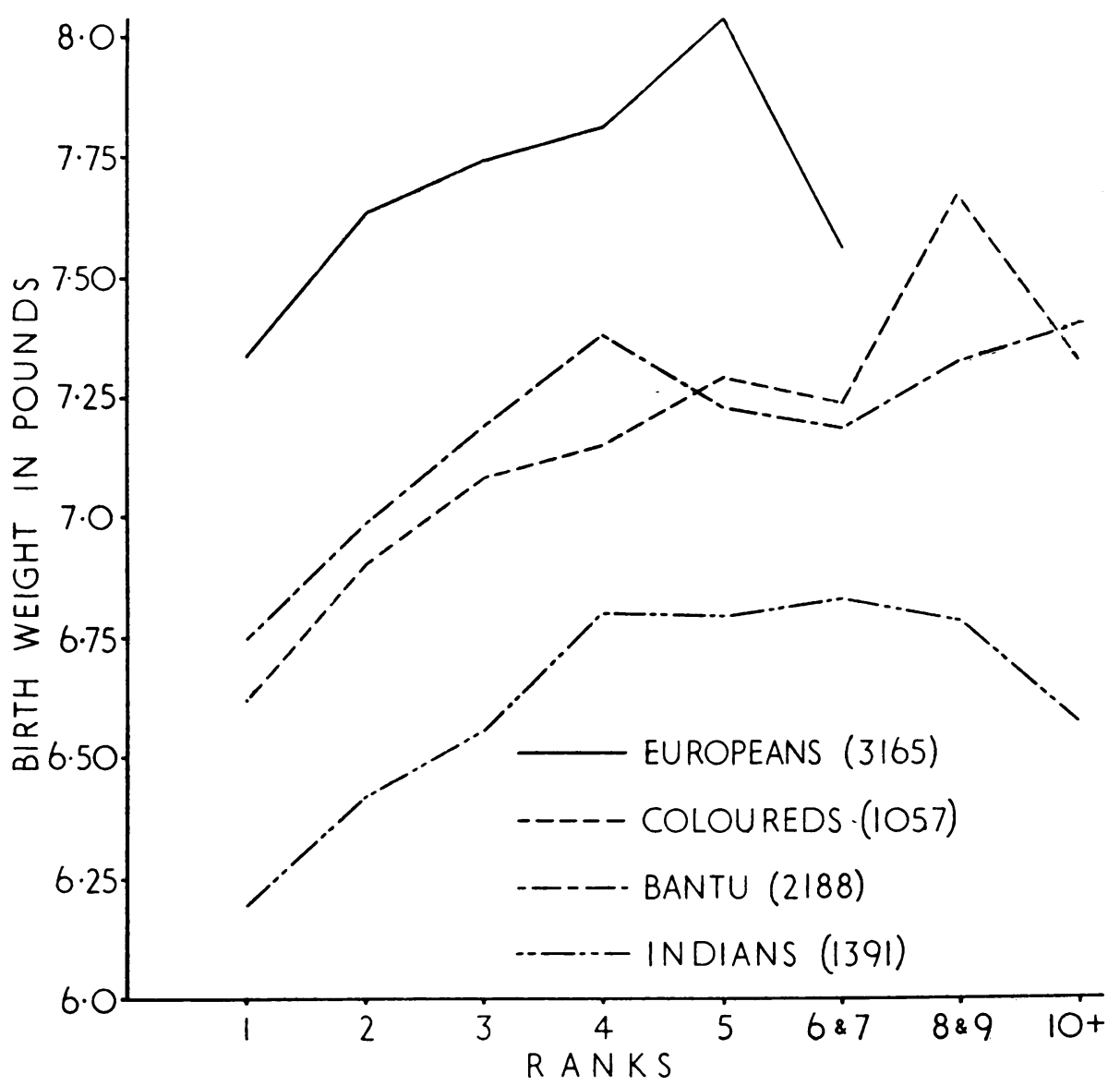

FIGURE. - Birth weight according to birth rank.

TABLE II

Mean Birth Weight Related to Birth Rank

\begin{tabular}{|c|c|c|c|c|c|c|c|c|c|c|c|c|}
\hline \multirow{2}{*}{ Birth Rank } & \multicolumn{3}{|c|}{ European } & \multicolumn{3}{|c|}{ Coloured } & \multicolumn{3}{|c|}{ Bantu } & \multicolumn{3}{|c|}{ Indian } \\
\hline & $\begin{array}{l}\text { No. of } \\
\text { Births }\end{array}$ & $\begin{array}{c}\text { Mean } \\
\text { (lb.) }\end{array}$ & S.D. & $\begin{array}{l}\text { No. of } \\
\text { Births }\end{array}$ & $\underset{\text { Mean }}{\text { (lb.) }}$ & S.D. & $\begin{array}{l}\text { No. of } \\
\text { Births }\end{array}$ & $\begin{array}{c}\text { Mean } \\
\text { (lb.) }\end{array}$ & S.D. & $\begin{array}{l}\text { No. of } \\
\text { Births }\end{array}$ & $\begin{array}{c}\text { Mean } \\
\text { (lb.) }\end{array}$ & S.D. \\
\hline $\begin{array}{c}1 \\
2 \\
3 \\
4 \\
5 \\
6 \text { and } 7 \\
8 \text { and } 9 \\
10 \text { and over }\end{array}$ & $\begin{array}{r}1,551 \\
1,013 \\
430 \\
101 \\
40 \\
21 \\
7 \\
2\end{array}$ & \begin{tabular}{|c|}
$7 \cdot 34$ \\
$7 \cdot 64$ \\
$7 \cdot 74$ \\
$7 \cdot 81$ \\
$8 \cdot 03$ \\
$7 \cdot 56$ \\
- \\
-
\end{tabular} & $\begin{array}{l}1 \cdot 13 \\
1 \cdot 14 \\
1 \cdot 15 \\
1 \cdot 31 \\
1 \cdot 26 \\
1 \cdot 26 \\
-\end{array}$ & \begin{tabular}{r|}
394 \\
255 \\
128 \\
80 \\
50 \\
78 \\
40 \\
32
\end{tabular} & $\begin{array}{l}6 \cdot 63 \\
6 \cdot 90 \\
7 \cdot 08 \\
7 \cdot 15 \\
7 \cdot 29 \\
7 \cdot 24 \\
7 \cdot 68 \\
7 \cdot 33\end{array}$ & $\begin{array}{l}1.09 \\
1.12 \\
1.08 \\
1.48 \\
1.03 \\
1.70 \\
1 \cdot 20 \\
1.63\end{array}$ & $\begin{array}{r}701 \\
562 \\
360 \\
206 \\
141 \\
140 \\
48 \\
30\end{array}$ & $\begin{array}{l}6 \cdot 75 \\
6 \cdot 99 \\
7 \cdot 19 \\
7 \cdot 38 \\
7 \cdot 23 \\
7 \cdot 18 \\
7 \cdot 33 \\
7 \cdot 40\end{array}$ & $\begin{array}{l}0.98 \\
1.13 \\
1.07 \\
1 \cdot 29 \\
1.15 \\
1.38 \\
1.09 \\
1.01\end{array}$ & $\begin{array}{r}404 \\
261 \\
175 \\
129 \\
112 \\
147 \\
92 \\
71\end{array}$ & $\begin{array}{l}6 \cdot 20 \\
6 \cdot 43 \\
6 \cdot 55 \\
6 \cdot 79 \\
6 \cdot 79 \\
6 \cdot 82 \\
6 \cdot 76 \\
6 \cdot 58\end{array}$ & $\begin{array}{l}0.99 \\
1 \cdot 11 \\
0.96 \\
1 \cdot 16 \\
1 \cdot 32 \\
1.49 \\
1 \cdot 32 \\
1.54\end{array}$ \\
\hline Total & 165 & $7 \cdot 52$ & $1 \cdot 16$ & 1,057 & 6.93 & $1 \cdot 23$ & 2,188 & $7 \cdot 03$ & $1 \cdot 11$ & 1,391 & $6 \cdot 51$ & $1 \cdot 19$ \\
\hline
\end{tabular}


TABLE III

Mean Birth Weight for each Sex related to Birth Rank

\begin{tabular}{|c|c|c|c|c|c|c|c|c|}
\hline \multirow{2}{*}{ Birth Rank } & \multicolumn{4}{|c|}{ Mean (lb.) Male } & \multicolumn{4}{|c|}{ Mean (lb.) Female } \\
\hline & European & Coloured & Bantu & Indian & European & Coloured & Bantu & Indian \\
\hline $\begin{array}{c}1 \\
2 \\
3 \\
4 \text { and over }\end{array}$ & $\begin{array}{l}7 \cdot 43 \\
7.73 \\
7 \cdot 87 \\
7.92\end{array}$ & $\begin{array}{l}6 \cdot 67 \\
6 \cdot 86 \\
7 \cdot 27 \\
7 \cdot 48\end{array}$ & $\begin{array}{l}6 \cdot 85 \\
7 \cdot 13 \\
7 \cdot 28 \\
7 \cdot 44\end{array}$ & $\begin{array}{l}6 \cdot 22 \\
6 \cdot 37 \\
6 \cdot 78 \\
6 \cdot 88\end{array}$ & $\begin{array}{l}7 \cdot 21 \\
7 \cdot 52 \\
7 \cdot 63 \\
7 \cdot 79\end{array}$ & $\begin{array}{l}6 \cdot 55 \\
6 \cdot 90 \\
6 \cdot 92 \\
7 \cdot 10\end{array}$ & $\begin{array}{l}6 \cdot 63 \\
6 \cdot 81 \\
7 \cdot 09 \\
7 \cdot 12\end{array}$ & $\begin{array}{l}6 \cdot 16 \\
6 \cdot 47 \\
6 \cdot 24 \\
6 \cdot 65\end{array}$ \\
\hline
\end{tabular}

$P<0.01$ for differences between means of all racial groups except:

MALE: Coloured and Bantu (all birth ranks).

Female: Coloured and Bantu (all birth ranks).

European and Coloured ( 4 and over. $P<0 \cdot 05$ ).

\section{Discussion}

Meredith and Brown (1939), in a review of the literature on the relation between birth order and mean weight at birth, found that all investigators agreed that later-born babies exceeded firstborn babies in mean birth weight. There does not seem to be unanimity, however, as to whether the birth weight becomes progressively greater with each increasing birth rank. One of the difficulties encountered by most investigators, including ourselves, is the paucity of numbers in the higher birth ranks. For this reason many investigators group their birth ranks.

Meredith and Brown divided their cases into firstborn, second- to fourth-born, and fifth and higher ranks. Of these three groups, they found that the second- to fourth-born had a higher mean birth weight than the firstborn; and that the fifth- and later-born had a higher mean birth weight than the second- to fourthborn. They also quote Perlstein and Levinson (1937), who found that birth weight increases with the parity of the mother up to the seventh, after which it decreases.

Bakwin and Bakwin (1934) state that birth weight increases up to the sixth pregnancy, after which it declines. Martin (1931) gave results for his mean birth weights for individual ranks up to 16 , and found that

the weight of the later-born exceeds that of the firstborn but it seems doubtful whether weight follows a progression with the rank of birth.

Donald (1939) quotes other workers in this field, and concludes that

most investigators agree that there is an increase in weight up to the third child. What happens after that has not been satisfactorily determined owing to the inadequacy of the available numbers, but it seems likely that there is but slight change from the fourth onwards.

McKeown and Gibson (1951) found that weight increases with parity to the third birth rank, but above the third there is no consistent change (at least none is evident when Rank 3 is compared with Rank 4 and over). 
In this series, the results were different for the different racial groups, except for the fact that all groups showed an increase in mean birth weight up to Rank 4. The Europeans showed their peak birth weight at Rank 5, with a drop thereafter. The Coloureds showed an almost steady rise to a peak at Ranks 8 and 9, followed by a drop. The Indians rose to a peak at Rank 4, remained virtually stationary to Ranks 8 and 9, and then dropped. The Bantu rose to a peak at Rank 4, dropped slightly for Ranks 5, 6, and 7, and rose again to a second peak at Rank $10+$.

We have observed previously (see Table I) that the percentage distribution of ranks found was different for the racial groups. It is possible that the age distribution of the mothers in the different ranks is also likely to differ in the racial groups. Whether this may account for some of the differences found between the four groups is not yet known, and is in the process of investigation.

\section{SUMMARY}

Birth weights of infants were studied with special reference to birth rank. The material comprised 3,165 European babies, 1,057 Coloured babies, 2,188 Bantu babies, and 1,391 Indian babies. Results were as follows:

(1) Distribution of birth ranks. Far more babies of higher birth rank were found in the Coloured, Bantu, and Indian groups than in the European group, with 5 per cent. of Indian babies of 10 th or higher birth rank.

(2) Mean birth weight increases with increasing birth rank up to Rank 4 in all racial groups. In no case is there a steady progression up to the highest rank. After Rank 4 the pattern is not consistent for the various groups. The only significant differences found were between Rank 1 and the higher ranks.

(3) The racial differences in mean birth weights which were noted in our previous paper are not due to differences in birth rank distribution of the babies in each race group. The present report indicates that these differences are to be found when comparing the various groups of babies of the same birth rank.

We wish to thank Dr. G. W. Gale, Secretary for Health, Union Health Department, for permission to publish this paper, Dr. S. L. Kark, Medical Officer-in-Charge, Institute of Family and Community Health, Durban, for his continued help, Mrs. E. Braude for the extraction of data from records in Pietermaritzburg, and Mr. L. V. Bradshaw for drawing the Figure. We are also indebted to the staffs of the various hospitals who so kindly co-operated in placing their records at our disposal.

\section{REFERENCES}

Bakwin, H., and Bakwin, R. M. (1934). Hum. Biol., 6, 612.

Donald, H. P. (1939). Proc. roy. Soc. Edinb., 59, 91.

Martin, W. J. (1931). Ann. Eugen., 4, 327.

McKeown, T., and Gibson, J. R. (1951). British Journal of Social Medicine, 5, 98.

Meredith, H. V., and Brown, A. W. (1939). Hum. Biol., 11, 24.

Perlstein, M. A., and Levinson, A. (1937). Amer. J. Dis. Child., 53, 1645.

Salber, E. J., and Bradshaw, E. S. (1951). British Journal of Social Medicine, 5, 113. 
Distribution OF BIRTH

\begin{tabular}{|c|c|c|c|c|c|c|c|c|c|c|c|}
\hline \multirow{3}{*}{$\begin{array}{c}\text { Birth } \\
\text { Weight } \\
\text { (lb.) }\end{array}$} & \multicolumn{11}{|c|}{ Birth Rank } \\
\hline & \multicolumn{2}{|c|}{1} & \multicolumn{2}{|c|}{2} & \multicolumn{2}{|c|}{3} & \multicolumn{2}{|c|}{4 and Over } & \multicolumn{3}{|c|}{ All Birth Ranks } \\
\hline & $\mathbf{M}$ & $\mathrm{F}$ & $\mathbf{M}$ & $\mathrm{F}$ & $\mathbf{M}$ & $\mathrm{F}$ & $\mathbf{M}$ & $\mathbf{F}$ & $\mathbf{M}$ & F & Total \\
\hline $\begin{array}{c}1- \\
1 \frac{1}{2}- \\
2- \\
2 \frac{1}{2}- \\
3- \\
3 \frac{1}{2}- \\
4- \\
4 \frac{1}{2}- \\
5- \\
5 \frac{1}{2}- \\
6- \\
6 \frac{1}{2}- \\
7- \\
7 \frac{1}{2}- \\
8- \\
8 \frac{1}{2}- \\
9- \\
9 \frac{1}{2}- \\
10- \\
10 \frac{1}{2}- \\
11- \\
11 \frac{1}{2}- \\
12- \\
12 \frac{1}{2}- \\
13-\end{array}$ & $\begin{array}{c}\text { (a) } E u \\
- \\
-1 \\
-3 \\
-7 \\
8 \\
20 \\
34 \\
81 \\
107 \\
159 \\
124 \\
149 \\
62 \\
37 \\
16 \\
9 \\
1 \\
= \\
- \\
- \\
-\end{array}$ & $\begin{array}{r}\text { eean } \\
- \\
2 \\
3 \\
1 \\
3 \\
11 \\
16 \\
48 \\
87 \\
128 \\
141 \\
128 \\
90 \\
45 \\
20 \\
6 \\
3 \\
1 \\
- \\
- \\
- \\
-\end{array}$ & $\begin{array}{r}- \\
-1 \\
1 \\
2 \\
1 \\
2 \\
3 \\
6 \\
15 \\
36 \\
50 \\
63 \\
113 \\
87 \\
59 \\
36 \\
16 \\
5 \\
1 \\
1 \\
- \\
- \\
-1\end{array}$ & $\begin{array}{l}- \\
\overline{-} \\
\overline{-} \\
- \\
2 \\
3 \\
12 \\
15 \\
42 \\
82 \\
99 \\
93 \\
80 \\
42 \\
28 \\
7 \\
4 \\
4 \\
1 \\
- \\
- \\
-\end{array}$ & $\begin{array}{l}- \\
= \\
- \\
-2 \\
-1 \\
4 \\
9 \\
10 \\
19 \\
32 \\
31 \\
42 \\
26 \\
16 \\
11 \\
7 \\
- \\
1 \\
= \\
- \\
-\end{array}$ & $\begin{array}{c}- \\
= \\
1 \\
- \\
-1 \\
2 \\
7 \\
21 \\
23 \\
47 \\
42 \\
27 \\
27 \\
14 \\
6 \\
1 \\
- \\
- \\
- \\
- \\
-\end{array}$ & $\begin{array}{l}-1 \\
- \\
= \\
- \\
- \\
1 \\
-2 \\
7 \\
4 \\
14 \\
22 \\
9 \\
13 \\
8 \\
3 \\
3 \\
1 \\
1 \\
- \\
- \\
-\end{array}$ & $\begin{array}{l}- \\
= \\
= \\
- \\
1 \\
2 \\
-2 \\
7 \\
10 \\
10 \\
13 \\
14 \\
10 \\
6 \\
4 \\
1 \\
2 \\
- \\
= \\
- \\
-\end{array}$ & $\begin{array}{r}-1 \\
2 \\
1 \\
5 \\
3 \\
9 \\
13 \\
30 \\
60 \\
134 \\
180 \\
268 \\
290 \\
287 \\
160 \\
97 \\
46 \\
24 \\
3 \\
3 \\
- \\
- \\
-1\end{array}$ & $\begin{array}{r}- \\
- \\
2 \\
4 \\
1 \\
6 \\
17 \\
30 \\
72 \\
157 \\
243 \\
297 \\
276 \\
211 \\
124 \\
68 \\
23 \\
9 \\
7 \\
1 \\
- \\
- \\
- \\
-\end{array}$ & $\begin{array}{r}- \\
1 \\
2 \\
3 \\
9 \\
4 \\
15 \\
30 \\
60 \\
132 \\
291 \\
423 \\
565 \\
566 \\
498 \\
284 \\
165 \\
69 \\
33 \\
10 \\
4 \\
- \\
- \\
-1 \\
\end{array}$ \\
\hline Total & 818 & 733 & 499 & 514 & 211 & 219 & 89 & 82 & 1,617 & 1,548 & 3,165 \\
\hline $\begin{array}{c}2- \\
2 \frac{1}{2}- \\
3- \\
3 \frac{1}{2}- \\
4- \\
4 \frac{1}{2}- \\
5- \\
5 \frac{1}{2}- \\
6- \\
6 \frac{1}{2}- \\
7- \\
7 \frac{1}{2}- \\
8- \\
8 \frac{1}{2}- \\
9- \\
9 \frac{1}{2}- \\
10- \\
10 \frac{1}{2}- \\
11- \\
11 \frac{1}{2}- \\
12-\end{array}$ & (b) $\begin{array}{c}C \\
1 \\
- \\
1 \\
1 \\
5 \\
4 \\
12 \\
27 \\
35 \\
46 \\
25 \\
21 \\
12 \\
11 \\
3 \\
- \\
- \\
- \\
- \\
-\end{array}$ & $\begin{array}{r}\text { ured } \\
1 \\
-1 \\
1 \\
1 \\
5 \\
2 \\
14 \\
19 \\
48 \\
40 \\
23 \\
24 \\
10 \\
2 \\
- \\
- \\
- \\
- \\
- \\
-\end{array}$ & $\begin{array}{r}= \\
= \\
-1 \\
1 \\
4 \\
71 \\
21 \\
21 \\
18 \\
20 \\
12 \\
5 \\
1 \\
3 \\
= \\
= \\
-\end{array}$ & $\begin{array}{r}- \\
-1 \\
1 \\
2 \\
-6 \\
61 \\
21 \\
17 \\
30 \\
13 \\
10 \\
5 \\
3 \\
1 \\
= \\
= \\
-\end{array}$ & $\begin{array}{c}= \\
= \\
-1 \\
-2 \\
4 \\
6 \\
9 \\
14 \\
8 \\
10 \\
7 \\
= \\
= \\
= \\
= \\
-\end{array}$ & $\begin{array}{r}- \\
-1 \\
-1 \\
- \\
2 \\
9 \\
10 \\
11 \\
16 \\
8 \\
3 \\
3 \\
= \\
= \\
= \\
-\end{array}$ & $\begin{array}{r}1 \\
1 \\
2 \\
2 \\
3 \\
-1 \\
1 \\
6 \\
11 \\
21 \\
15 \\
29 \\
17 \\
10 \\
9 \\
5 \\
4 \\
-1 \\
-1 \\
1\end{array}$ & $\begin{array}{r}- \\
-1 \\
3 \\
3 \\
1 \\
-14 \\
20 \\
26 \\
22 \\
20 \\
15 \\
8 \\
1 \\
2 \\
4 \\
1 \\
- \\
-\end{array}$ & $\begin{array}{r}2 \\
1 \\
3 \\
3 \\
10 \\
8 \\
22 \\
58 \\
72 \\
97 \\
72 \\
79 \\
51 \\
33 \\
13 \\
8 \\
4 \\
-1 \\
-1\end{array}$ & $\begin{array}{r}1 \\
-4 \\
5 \\
11 \\
3 \\
22 \\
53 \\
99 \\
94 \\
91 \\
65 \\
38 \\
18 \\
7 \\
3 \\
4 \\
1 \\
- \\
-\end{array}$ & $\begin{array}{r}3 \\
1 \\
7 \\
8 \\
21 \\
11 \\
44 \\
111 \\
171 \\
191 \\
163 \\
144 \\
89 \\
51 \\
20 \\
11 \\
8 \\
1 \\
1 \\
- \\
1\end{array}$ \\
\hline Total & 204 & 190 & 134 & 121 & 61 & 67 & 139 & 141 & 538 & 519 & 1,057 \\
\hline
\end{tabular}


NDIX

Weights at each Birth Rank

\begin{tabular}{|c|c|c|c|c|c|c|c|c|c|c|c|}
\hline \multirow{3}{*}{$\begin{array}{l}\text { Birth } \\
\text { Weight } \\
\text { (lb.) }\end{array}$} & & & & & \multicolumn{4}{|c|}{ Birth Rank } & & & \\
\hline & \multicolumn{2}{|c|}{1} & \multicolumn{2}{|c|}{2} & \multicolumn{2}{|c|}{3} & \multicolumn{2}{|c|}{4 and Over } & \multicolumn{3}{|c|}{ All Birth Ranks } \\
\hline & $\mathbf{M}$ & $F$ & $\mathbf{M}$ & $\mathbf{F}$ & $\mathbf{M}$ & F & $\mathbf{M}$ & F & $\mathbf{M}$ & F & Total \\
\hline $\begin{array}{c}1 \frac{1}{2}- \\
2- \\
2 \frac{1}{2}- \\
3- \\
3 \frac{1}{2}- \\
4- \\
4 \frac{1}{2}- \\
5- \\
5 \frac{1}{2}- \\
6- \\
6 \frac{1}{2}- \\
7- \\
7 \frac{1}{2}- \\
8- \\
8 \frac{1}{2}- \\
9- \\
9 \frac{1}{2}- \\
10- \\
10 \frac{1}{2}- \\
11-\end{array}$ & $\begin{array}{r}\text { (c) } B c \\
- \\
-1 \\
-2 \\
2 \\
3 \\
8 \\
12 \\
28 \\
48 \\
93 \\
68 \\
44 \\
20 \\
12 \\
1 \\
2 \\
1 \\
-\end{array}$ & $\begin{array}{r}-2 \\
-1 \\
1 \\
2 \\
1 \\
6 \\
17 \\
42 \\
92 \\
80 \\
55 \\
36 \\
16 \\
5 \\
3 \\
- \\
- \\
-\end{array}$ & $\begin{array}{r}1 \\
1 \\
2 \\
-1 \\
4 \\
3 \\
12 \\
6 \\
34 \\
49 \\
66 \\
39 \\
28 \\
17 \\
7 \\
4 \\
1 \\
1 \\
-\end{array}$ & $\begin{array}{r}1 \\
- \\
2 \\
-4 \\
4 \\
11 \\
18 \\
50 \\
74 \\
51 \\
47 \\
15 \\
7 \\
1 \\
1 \\
- \\
-\end{array}$ & $\begin{array}{r}\overline{2} \\
- \\
-1 \\
1 \\
- \\
4 \\
11 \\
27 \\
24 \\
49 \\
37 \\
28 \\
12 \\
5 \\
2 \\
1 \\
1 \\
-\end{array}$ & $\begin{array}{r}- \\
\bar{Z} \\
\overline{ } \\
2 \\
1 \\
5 \\
8 \\
25 \\
33 \\
32 \\
24 \\
12 \\
9 \\
4 \\
- \\
- \\
-\end{array}$ & $\begin{array}{r}1 \\
2 \\
1 \\
1 \\
2 \\
4 \\
-7 \\
10 \\
23 \\
46 \\
54 \\
55 \\
39 \\
34 \\
15 \\
4 \\
3 \\
1 \\
1\end{array}$ & $\begin{array}{r}- \\
- \\
1 \\
4 \\
2 \\
3 \\
8 \\
16 \\
35 \\
49 \\
48 \\
47 \\
20 \\
16 \\
8 \\
2 \\
3 \\
- \\
-\end{array}$ & $\begin{array}{r}2 \\
5 \\
4 \\
1 \\
6 \\
12 \\
11 \\
35 \\
55 \\
132 \\
212 \\
237 \\
175 \\
115 \\
75 \\
28 \\
12 \\
6 \\
3 \\
1\end{array}$ & $\begin{array}{r}1 \\
2 \\
-4 \\
6 \\
9 \\
14 \\
41 \\
84 \\
202 \\
236 \\
186 \\
154 \\
63 \\
37 \\
16 \\
3 \\
3 \\
- \\
-\end{array}$ & $\begin{array}{r}3 \\
7 \\
4 \\
5 \\
12 \\
21 \\
25 \\
76 \\
139 \\
334 \\
448 \\
423 \\
329 \\
178 \\
112 \\
44 \\
15 \\
9 \\
3 \\
1\end{array}$ \\
\hline Total & 343 & 358 & 276 & 286 & 205 & 155 & 303 & 262 & 1,127 & 1,061 & 2,188 \\
\hline
\end{tabular}

\begin{tabular}{|c|c|c|c|c|c|c|c|c|c|c|c|}
\hline & (d) $I$ & & & & & & & & & & \\
\hline $1-$ & - & - & - & - & - & - & 1 & 2 & 1 & 2 & 3 \\
\hline $2^{\frac{1}{2}-}$ & - & - & 1 & - & - & - & - & - & 1 & - & 1 \\
\hline $2 \frac{1}{2}-$ & 2 & 1 & - & E & 二 & - & 1 & -1 & 3 & $\overline{2}$ & 25 \\
\hline 3 & 1 & 1 & 4 & - & - & - & 2 & 5 & 7 & 6 & 13 \\
\hline $3 \frac{1}{2}-$ & - & 1 & 3 & 1 & - & - & 4 & 3 & 7 & 5 & 12 \\
\hline $4-$ & 3 & 8 & 4 & - & 1 & 2 & 1 & 7 & 9 & 17 & 26 \\
\hline $4 \frac{1}{2}-$ & I & 13 & 1 & 1 & 1 & 6 & 7 & 9 & 16 & 29 & 45 \\
\hline $5-$ & 34 & 28 & 11 & 18 & 7 & 10 & 15 & 16 & 67 & 72 & 139 \\
\hline $5 \frac{1}{2}-$ & 27 & 36 & 19 & 19 & 11 & 9 & 25 & 20 & 82 & 84 & 166 \\
\hline $6-$ & 46 & 41 & 30 & 30 & 17 & 20 & 38 & 58 & 131 & 149 & 280 \\
\hline $6 \frac{1}{2}-$ & 30 & 38 & 17 & 19 & 22 & 12 & 49 & 38 & 118 & 107 & 225 \\
\hline $7-$ & 31 & 28 & 24 & 24 & 20 & 8 & 48 & 51 & 123 & 111 & 234 \\
\hline $7 \frac{1}{2}-$ & 0 & 7 & 11 & 5 & 16 & 3 & 39 & 34 & 74 & 49 & 123 \\
\hline 8 & 4 & 6 & 7 & 4 & 6 & - 1 & 18 & 12 & 35 & 23 & 58 \\
\hline $8 \frac{1}{2}-$ & 2 & - & 2 & 4 & 1 & 1 & 16 & 6 & 21 & 11 & 32 \\
\hline & 一 & 1 & 1 & 1 & 一 & 1 & 6 & 6 & 7 & 9 & 16 \\
\hline $9 \frac{1}{2}-$ & - & - & - & - & - & - & 1 & 2 & 1 & 2 & 3 \\
\hline $10-$ & 一 & - & - & - & 一 & - & 2 & 4 & 2 & 4 & 6 \\
\hline $10 \frac{1}{2}-$ & - & - & - & - & - & - & 2 & - & 2 & - & 2 \\
\hline Total & 195 & 209 & 135 & 126 & 102 & 73 & 277 & 274 & 709 & 682 & 1,391 \\
\hline
\end{tabular}

